\title{
Performance of Lubricated Sliding Contact in Magnetic Field
}

\author{
T. A. Stolarski $\cdot$ Y. Makida
}

Received: 5 January 2012 / Accepted: 1 February 2012/Published online: 16 February 2012

(C) The Author(s) 2012. This article is published with open access at Springerlink.com

\begin{abstract}
Results of experimental studies concerning the influence of permanent magnetic field on wear of lubricated sliding contact operating at short stroke and high frequency are presented. It was found that horizontal magnetic is affecting performance of the contact. The jagged delamination regions produced in the presence of a magnetic field can be regarded as easily undergoing oxidisation because oxygen is readily adsorbed there. Magnetic field is likely to intensify the abrasive action by wear particles and mitigate wear of the plate specimen. It is postulated that all these effects are caused by the influence of magnetic field on the electrical charge of the worn surface created on Si3N4 ball.
\end{abstract}

Keywords Boundary lubrication - Magnetic particles · Wear mechanisms · Wear particle analysis

\section{Introduction}

The influence of magnetic field on sliding contact performance is an important problem especially nowadays with the advent of mechano-electrical devices such as, for example, magnetic data storage hard discs [1]. It has been

T. A. Stolarski: On sabbatical leave from Gdansk University of Technology.

T. A. Stolarski $(\bowtie) \cdot$ Y. Makida

Mechanical Engineering, School of Engineering and Design,

Brunel University, Uxbridge, Middlesex UB8 3PH, UK

e-mail: mesttas@brunel.ac.uk studied by a number of researchers using various experimental methods in order to clarify its effect on material properties and material behaviour.

According to Chikazumi [2], the magnetisation is insensitive to the applied low stress in the demagnetised state where the ferromagnetic material is not magnetising. Besides, magnetic field influences the plasticity of a ferromagnetic material according to Muju and Ghosh [3]. Also, it has been found by several researchers that the magnetic field changes the microhardness and mechanical properties of materials. The microhardness of the wear surface is an important factor for the tribological behaviour. Mansori et al. [4] performed microhardness measurements for the sliding surface of the ferromagnetic materials under the conditions of the magnetic field, $H=4.5 \times 10^{4} \mathrm{~A} \mathrm{~m}^{-1}$, and no magnetic field and found that the presence of vertical magnetic field increased microhardness. Not only Mansori but also Zaidi et al. [5] reported that the vertical magnetic field increased microhardness of sliding surface.

Yamamoto and Gondo [6] concluded that the surface reactivity was increased by magnetisation. Contrary to their report, Muju and Radhakrishna [7] stated the decrease of the wear activation energy with a magnetic field. Kumagai et al. $[8,9]$ and some other researchers reached the conclusion that a magnetic field affects the process by reducing the wear activation energy. In addition, they expressed the view that magnetisation promoted generation of the minute particles and oxidisation of the wear debris because the wear products were attracted by magnetic force and were held in the contact area.

The aim of the study presented in this article was to examine the effect of horizontal magnetic field on sliding contact wear performance and to clarify the mechanism of magnetic field action. Specific objectives included 
investigation of the effect of magnetic field direction relative to sliding path and its influence on contact lubrication.

\section{Experimental Techniques}

\subsection{Test Apparatus}

Lubricated sliding contact experiments were carried out using ball-on-plate contact configuration. Two permanent magnets were installed in the direction same as the ball sliding over the plate specimen. The apparatus is shown schematically in Fig. 1. The installation angles of the magnets relative to the sliding direction could be adjusted to $0^{\circ}, 45^{\circ}$ and $90^{\circ}$ as shown in Fig. 2 .

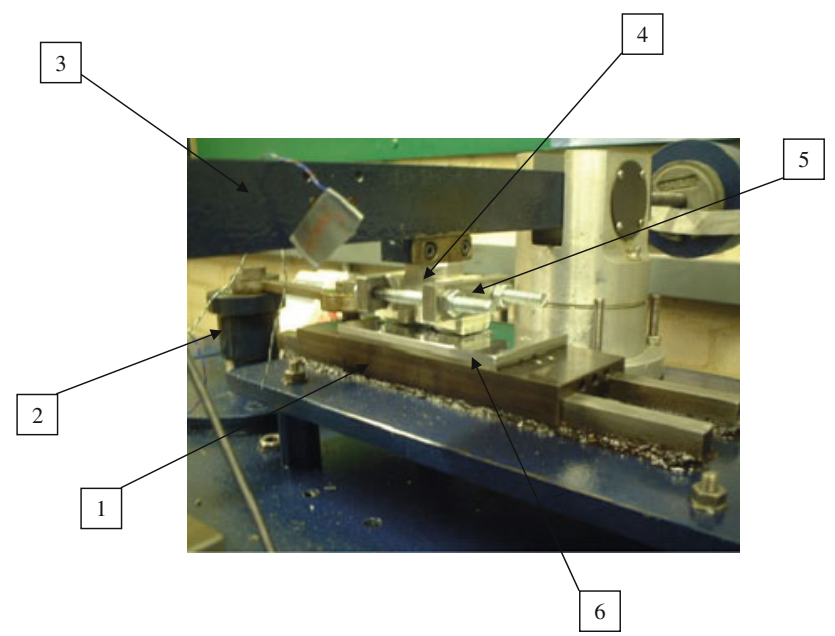

Fig. 1 Ball-on-plate apparatus. 1 Translating stage, 2 crank drive, 3 loading arm, 4 ball holder, 5 magnets holding brackets, 6 test plate

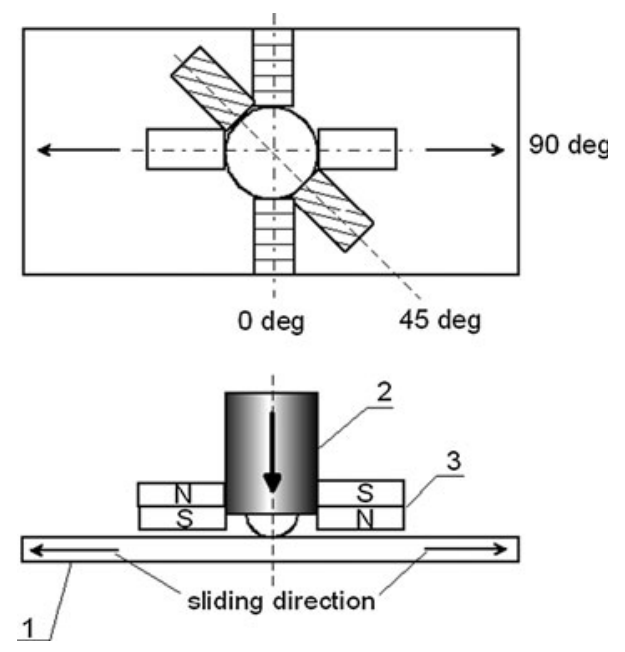

Fig. 2 Arrangement of magnets within the contact region. 1 Test plate, 2 ball and its holder (arrow denotes external loading on contact), 3 set of permanent magnets
Arrangements of magnets creating magnetic field perpendicular to the sliding direction was denoted $0^{\circ}$ and was exclusively used in the experiments reported in this article.

\subsection{Test Materials}

Test plate was made of a mild steel and was $65-\mathrm{mm}$ long, 20-mm wide, and had thickness of $4 \mathrm{~mm}$. Two holes at both ends of the plate were used to attach it to the moving stage of the test apparatus. Surface of the plate was polished with abrasive papers to reach roughness of about $0.32 \mu \mathrm{m}$. The plate was in sliding contact with a silicon nitride ball of $6.35-\mathrm{mm}$ diameter and had hardness of $1400 \mathrm{HV}$. Before each test, both the plate and the ball were thoroughly cleaned with acetone.

In the lubricated sliding wear test, commercially available engine oil was used. Its kinematic viscosity was 100 and $14.5 \mathrm{~mm}^{2} / \mathrm{s}$ at 40 and $100{ }^{\circ} \mathrm{C}$, respectively.

The horizontal magnetic field was produced by two types of permanent magnets. One was made of rare earth and its flux density was $1.1 \mathrm{~T}$. The other one was a ferrite magnet with flux density $0.4 \mathrm{~T}$. Magnets were located near the ends of the contact area and were attached to the ball holder in the sliding wear test machine. Therefore, the total contact load $P$ is a sum of attractive force $P_{\mathrm{m}}$ due to magnets and the normal load $P_{1}$ produced by dead weight.

\subsection{Lubrication Regime}

All tests were carried out under at the initial contact pressure of $925 \mathrm{MPa}$ estimated from Hertz's equation for a point contact (used contact configuration: ball-on-plate). Average sliding speed (because of the reciprocating motion) was $8.6 \mathrm{~mm} / \mathrm{s}$. The parameter $\lambda$, commonly used to decide on the lubrication regime [10], was equal to 0.03 therefore it can be said that lubrication within the contact region was of a boundary type.

\subsection{Details of Test Procedure}

Both plate and ball specimens were dried naturally after they were cleaned by acetone using an ultrasonic washing machine. Before the start of wear testing, weight and surface roughness were recorded and optical microscope observations of the surface were carried out. The plate was attached to the movable stage of the test apparatus and the ball was inserted into its holder. Permanent magnets were attached to a bracket with adhesive and cellophane tapes. The bracket was fastened to the ball holder with bolts. The bracket had a gap of $1 \mathrm{~mm}$ at the interface between the frame and permanent magnet. The arm of the testing 
machine was made horizontal with a spirit level. An enclosure was made on the stage in order to prevent leakage of lubricant from the contact area. The enclosure was made by $0.5-\mathrm{mm}$-thick plate and was $30 \mathrm{~mm}$ in length and $10 \mathrm{~mm}$ in width. The test plate was flooded with $0.2 \mathrm{ml}$ of lubricant. Contact between the plate and the ball was made when the plate was moving in a reciprocated motion.

The total load on the contact was the sum of the magnetic force and dead load because permanent magnets attracted the plate specimen. Resulting initial contact stresses were $925 \mathrm{MPa}$. The average sliding speed was $8.6 \mathrm{~mm} / \mathrm{s}$, and amplitude was $15 \mathrm{~mm}$ hence the corresponding frequency was $0.29 \mathrm{~Hz}$. The total number of sliding strokes was approximately $213 \times 10^{3}$. In order to examine the magnetic field effect on wear process, the tests were stopped every $24 \times 10^{3}$ strokes and weight measurements, the surface roughness measurements and the optical microscope observations were carried out.

\subsection{Post-Test Examinations}

Additional post-test examinations were carried out to evaluate the effect of magnetic field. They induced hardness measurements, observations of wear track on test specimens with scanning electron microscope (SEM) and X-ray diffraction (XRD) analyses. The distribution of wear debris on the plate specimen was investigated together with SEM observations and SEM analyses of wear particles. Moreover, the XRD analysis was undertaken. After cleaning test specimens, weight measurements, optical microscope observation and surface roughness measurement were carried out. Then, the plate specimen was cut and embedded in a resin and the cross-section polished. The cross-section of the wear track was used for an optical microscope and SEM observations.

\section{Presentation of Results}

\subsection{Accumulated Mass Loss of the Plate}

Figure 3 illustrates accumulated mass loss of the plate versus the number of sliding strokes under different magnetic field densities. The accumulated mass loss is proportional to the number of sliding strokes. In addition, the accumulated mass loss at $0 \mathrm{~T}$ (no magnetic field present) increases sharply from 8 to $184 \mathrm{mg}$ approximately, whilst the accumulated mass losses at both $0.4 \mathrm{~T}$ (magnetic flux density equal to $0.4 \mathrm{~T}$ ) and $1.1 \mathrm{~T}$ (magnetic flux density equal to $1.1 \mathrm{~T}$ ) increase steadily from 5 to $118 \mathrm{mg}$ approximately. In detailed comparison between 0.4 and $1.1 \mathrm{~T}$, the mass loss at $1.1 \mathrm{~T}$ is only greater by $0.4 \mathrm{mg}$. However, comparing that to mass loss at $0 \mathrm{~T}$, it is clear that the presence of the magnetic fields decrease the wear amount of the plate.

\subsection{Surface Roughness of the Wear Track Formed on the Plate}

Figure 4 illustrates changes in surface roughness of the wear track for different magnetic field densities. The surface roughness at $0 \mathrm{~T}$ changes sharply from 0.17 to $0.32 \mu \mathrm{m}$ during $72 \times 10^{3}$ strokes. In the case of $1.1 \mathrm{~T}$, the surface roughness increases gradually and is fluctuating between 0.25 and $0.41 \mu \mathrm{m}$ during $192 \times 10^{3}$ strokes, whilst the surface roughness at $0.4 \mathrm{~T}$ fluctuates approximately between 0.25 and $0.32 \mu \mathrm{m}$ during $72 \times 10^{3}$ strokes. After $96 \times 10^{3}$ strokes, all $R a$ values range from 0.25 to $0.42 \mu \mathrm{m}$, and increase slightly until $168 \times 10^{3}$ strokes are attained. Unexpectedly, surface roughness at 0 and $0.4 \mathrm{~T}$ decreases after $216 \times 10^{3}$ strokes, whilst the surface roughness at $1.1 \mathrm{~T}$ considerably decreased after $144 \times 10^{3}$ strokes. Thus, it can be said that the range of the surface
Fig. 3 Accumulated mass loss of the plate in difference magnet flux densities

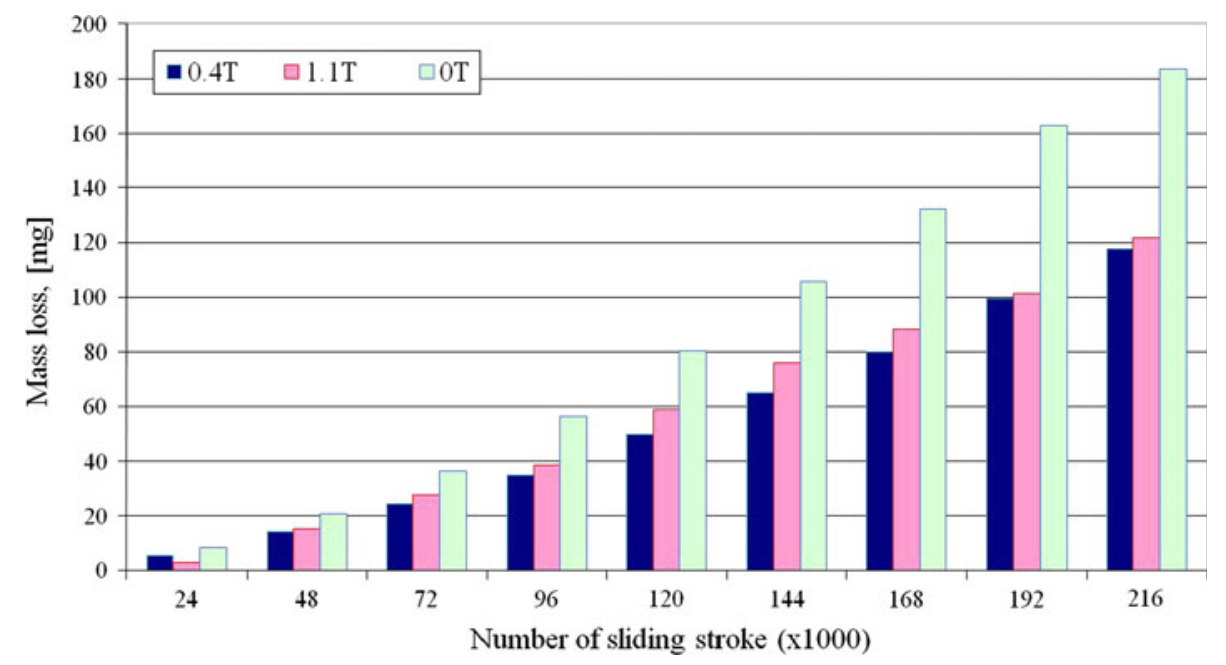


Fig. 4 Surface roughness of the plate created in different magnet flux densities

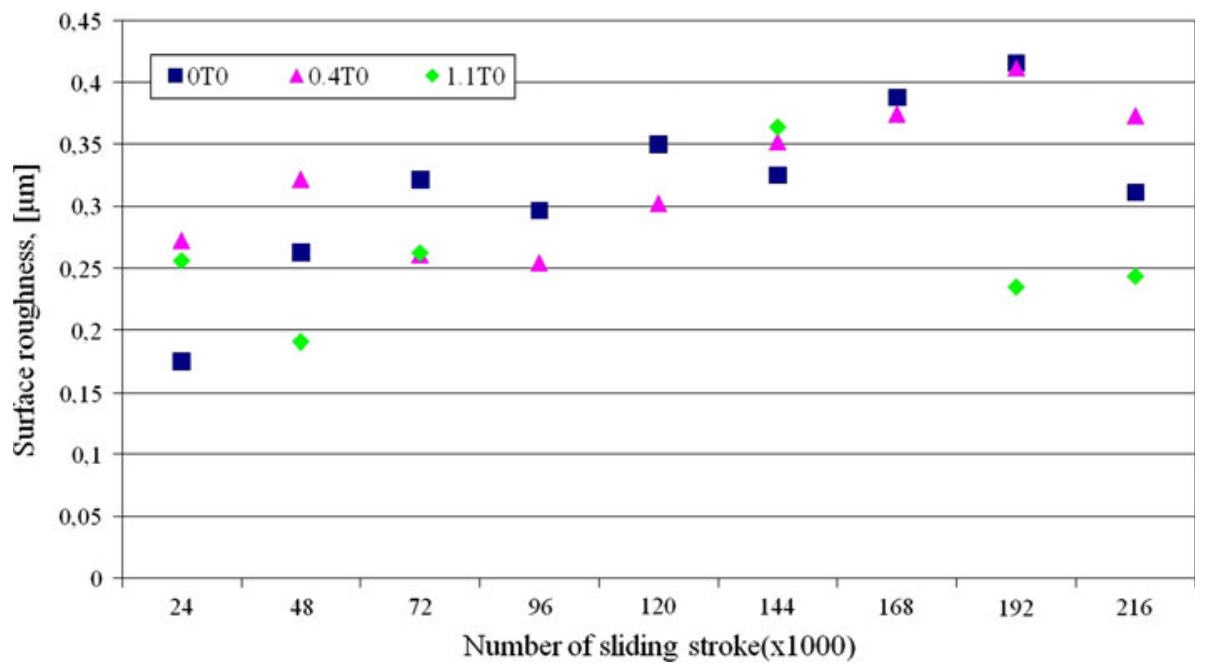

roughness changes somewhat narrows in the presence of the magnetic field.

\subsection{Appearance of the Wear Track Formed on Test Specimens}

Optical microscope images of wear tracks generated after 24 and $184 \times 10^{3}$ strokes were taken. They reveal that wear surface generated under the influence of the horizontal magnetic field is a smooth with arc-like shape similar to the wear track produced in the absence of the magnetic field. However, the magnetic field additionally produced a small jagged shape after $24 \times 10^{3}$ strokes.

The wear track at $0 \mathrm{~T}$ was $1.81 \mathrm{~mm}$ in width and $62.0 \mu \mathrm{m}$ in depth after $24 \times 10^{3}$ strokes and grew to $5.1 \mathrm{~mm}$ in width and $510 \mu \mathrm{m}$ in depth after $184 \times 10^{3}$ strokes. Whilst, in comparison, both the depth and width of the wear track at $0.4 \mathrm{~T}$ are almost of same sizes as the depth and width at $1.1 \mathrm{~T} 0$ and the same number of sliding strokes. Therefore, it appears that the influence of even relatively weak magnetic field $(0.4 \mathrm{~T})$ is significant and results in slight decrease in the wear of the plate.

Fine scratches are the main feature of wear surface produced at $1.1 \mathrm{~T}$ and $184 \times 10^{3}$ strokes. The observation of the surface was carried out at $50 \times$ magnification. At magnification of $50 \times$, signs of delamination and spalling could be seen on the wear track produced at $1.1 \mathrm{~T}$.

Figure 5 shows the wear track at high magnification. Symptoms of delamination can be observed on the wear track created in the presence of magnetic field.

\subsection{Wear Debris Observations}

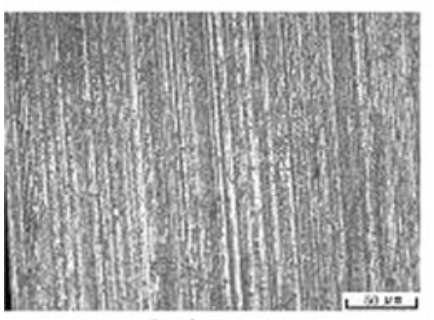

(c-1) Ball

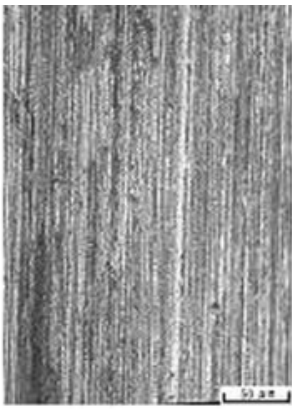

(a-2) Plate

(a) OTO

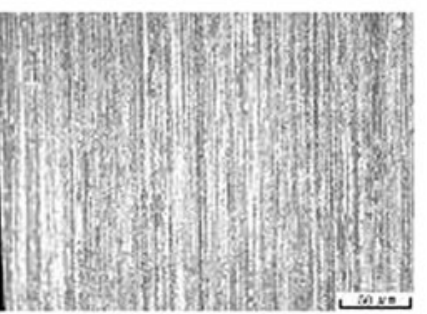

(b-1) Ball

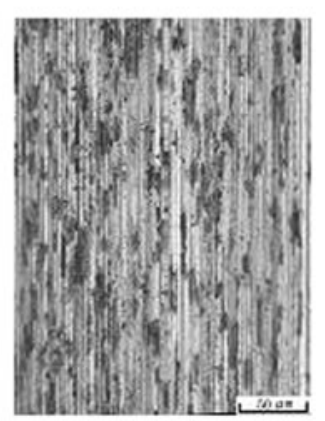

(b-2) Plate

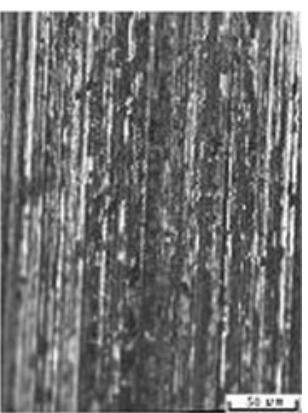

(c-2) Plate (c) $1.1 \mathrm{To}$

Fig. 5 Appearances of the wear surface on plates and balls after $72 \times 10^{3}$ strokes 
Fig. 6 General secondary images of wear debris $($ at $\times 500$ magnification)

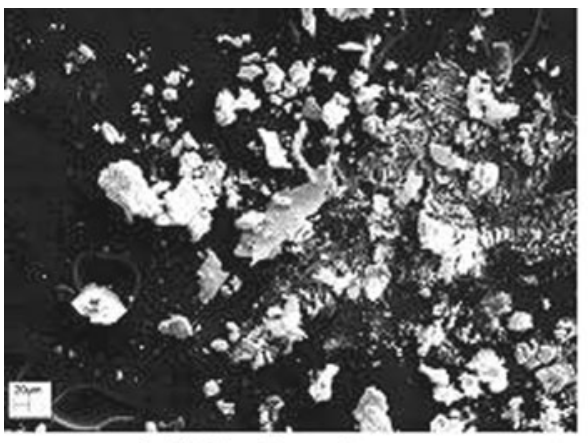

(a-1) $24 \times 10$ strokes

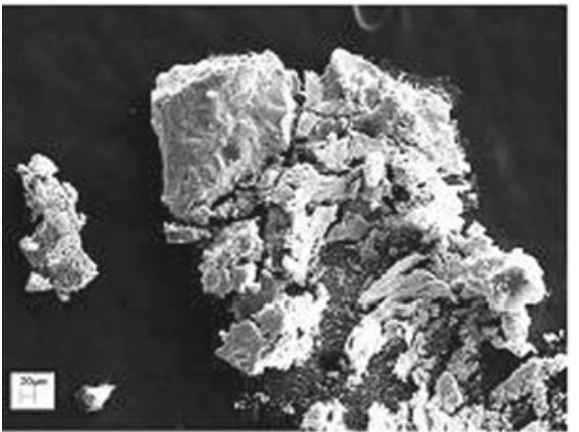

(b-1) 24810 s strokes

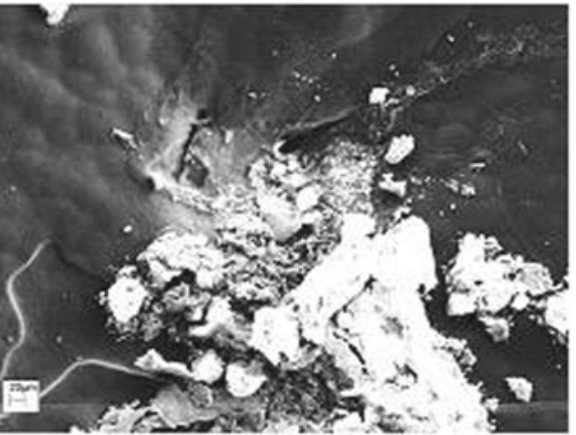

(c-1) $24 \times 10^{5}$ strokes (a) OTO

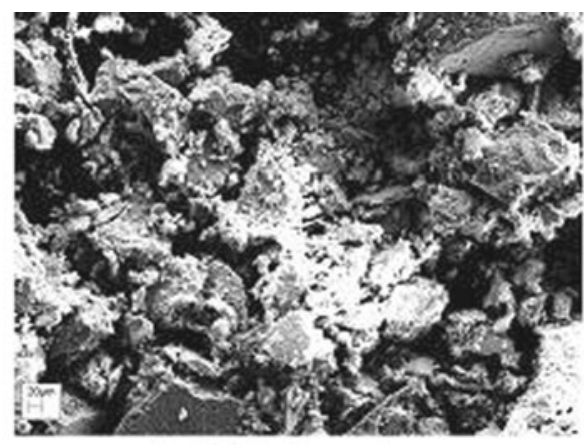

(a-2) $120 \times 105$ strokes

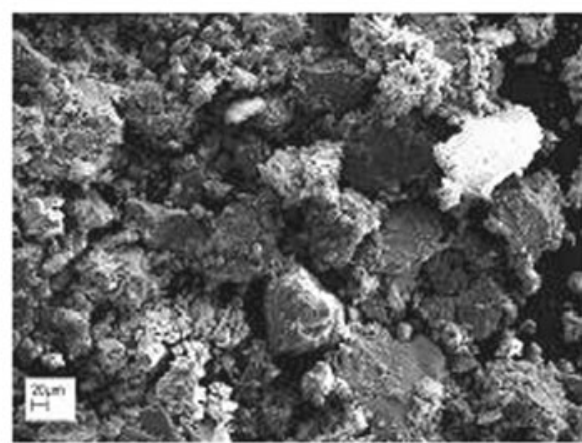

(b-2) $120 \times 10$ strokes

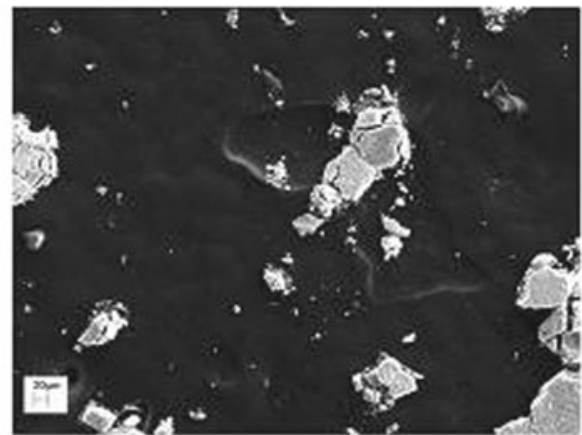

(c-2) $120 \times 10^{5}$ strokes

(c) $1.1 \mathrm{To}$

8). The element spectrum shows that wear debris consist of $\mathrm{C}, \mathrm{Ca}, \mathrm{Fe}, \mathrm{O}, \mathrm{S}$ and $\mathrm{Si}$. The $\mathrm{Ca}$ and $\mathrm{S}$ are lubricant additives. Oxygen peaks for both $0.4 \mathrm{~T} 0$ and $1.1 \mathrm{~T}$ conditions are high comparing to the oxygen peak at $0 \mathrm{~T}$.

The XRD analysis shown in Fig. 9 show that wear debris under different magnetic flux densities consist of $\alpha$-iron and $\mathrm{CaCO}_{3}$ (calcium carbonate). Besides, other weak peaks, which are $\mathrm{CaCO}_{3}$, are present at several points. Wear debris contain clear peak of $\mathrm{CaCO}_{3}$ which increases with magnetic field density. Highest peak was recorded for $1.1 \mathrm{~T} 0$ test condition. Therefore, SEM analyses suggest that the magnetic field enhances the oxidation of ferro-wear debris. Furthermore, the peaks of $\mathrm{CaCO}_{3}$ are increased due to the influence of the magnetic field. 
Fig. 7 Backscatter image and SEM analysis of wear particle created at $0.4 \mathrm{~T}$

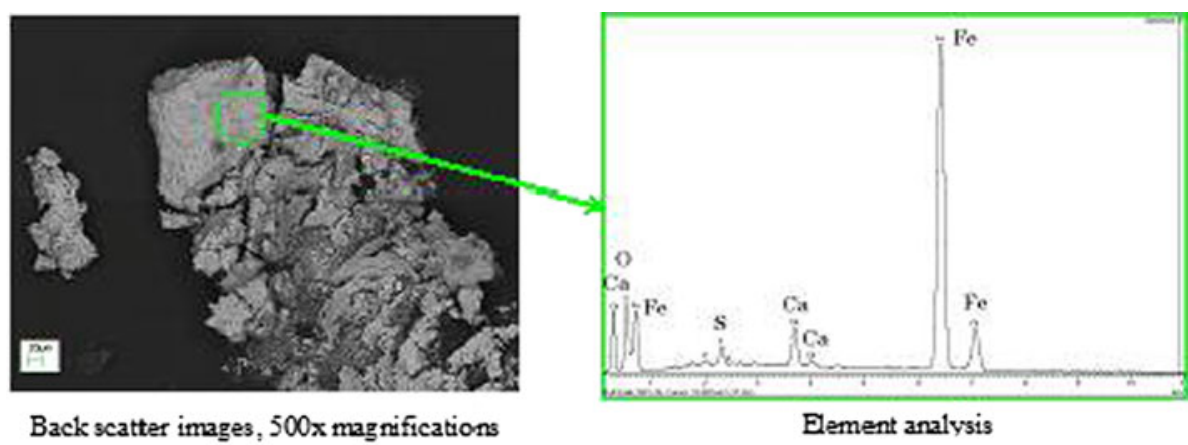

(a) $24 \times 10^{3}$ strokes

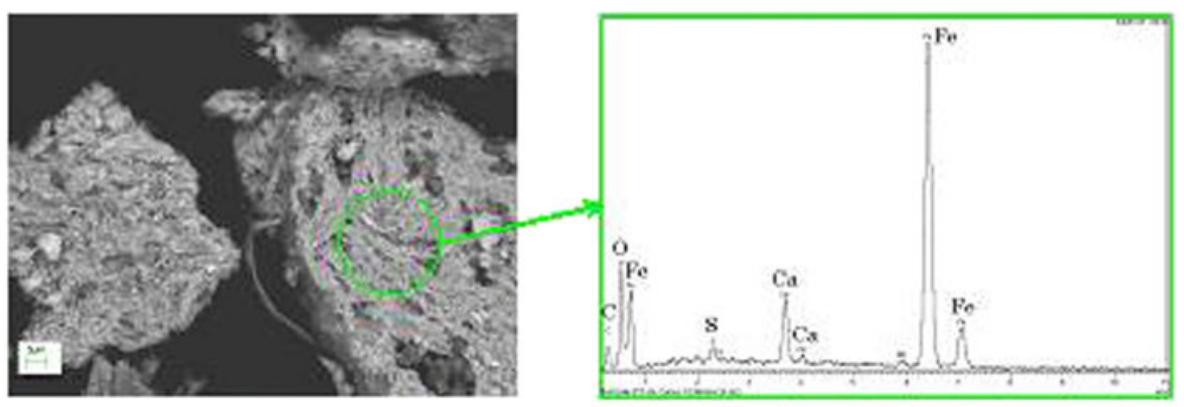

Back scatter images, $5,000 x$ magnifications

Element analvsis

(b) $92 \times 10^{3}$ strokes

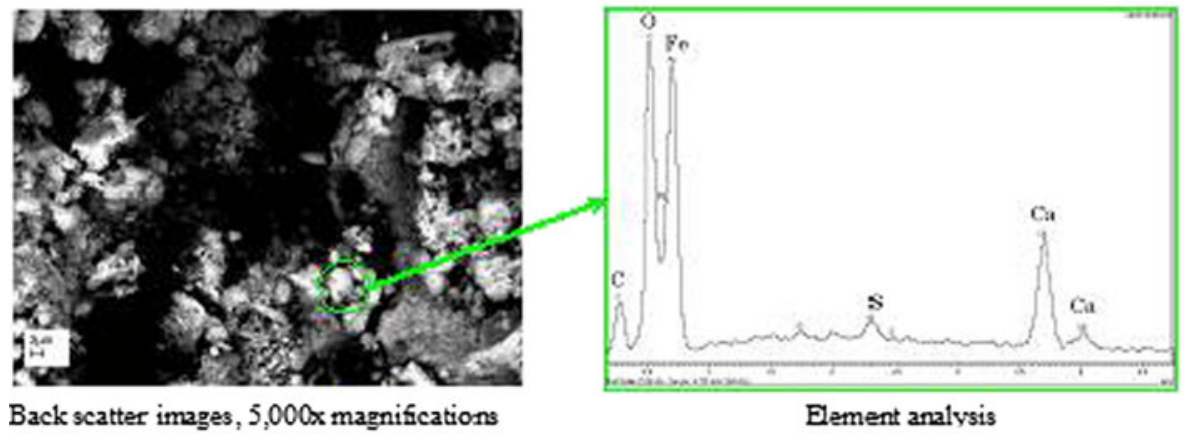

(c) $120 \times 10^{3}$ strokes

\section{Discussion}

The presence of magnetic field contributes to the wear reduction of lubricated sliding contacts however it does not affect the surface roughness of worn area of the plate specimen. The obvious question is, therefore, what is the reason that the reduction of mass loss took place but the surface roughness was not affected by the presence of magnetic field? There are two possible reasons for that. One is the removal of some iron wear particles by the magnetic field from the edges of the contact area whilst the remaining wear debris contained in the lubricant are kept there. The other one is that the generation of delamination regions on the wear track of the plate specimen takes place only in the presence of magnetic field and the strength of magnetic flux density is also a contributing factor to that.

\subsection{Magnetic Field Influence on Lubricant}

Generally speaking, adsorption of surface-active substances changes the deformation behaviour of nonferrous metals. In addition, if surface electrical charge on the wear surface of $\mathrm{Si}_{3} \mathrm{~N}_{4}$ ball is absent, Macmillan et al. [11] showed that the fluidity of lubricant is improved due to higher surface tension. Also, there is a reduction of the friction coefficient associated with high hardness. Therefore, it is postulated that the reduction of mass loss of the plate specimen is caused by the influence of magnetic field on the electrical charge of the wear surface of $\mathrm{Si}_{3} \mathrm{~N}_{4}$ ball.

The calcium sulphonate surfactants covering the surface of the plate specimen and forming a protective film can be reinserted and reformed in regions where the protective films are damaged due to abrasive action of oxidised wear 
Fig. 8 Backscatter image and SEM analysis of wear particle created at $1.1 \mathrm{~T}$

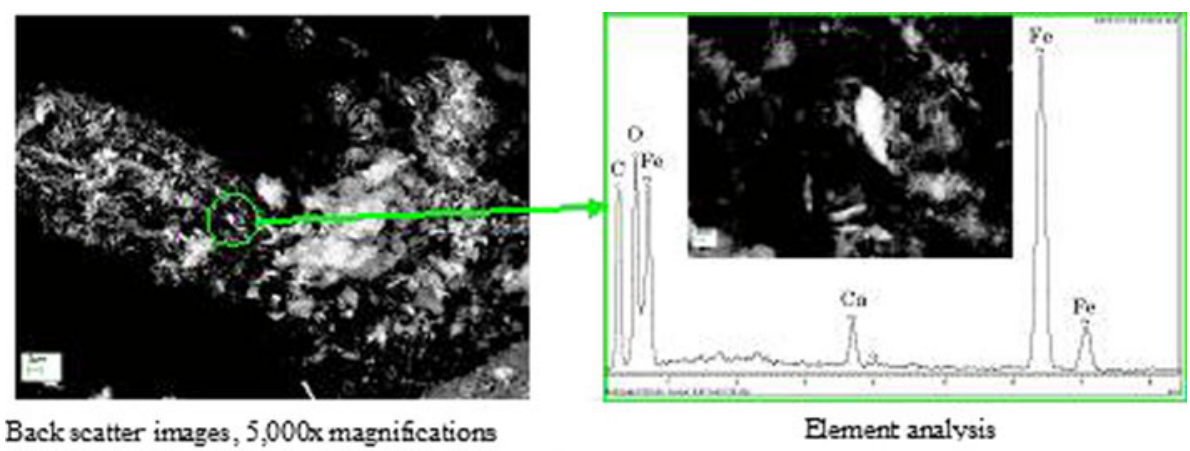

(a) $24 \times 10^{3} 3$ trokes

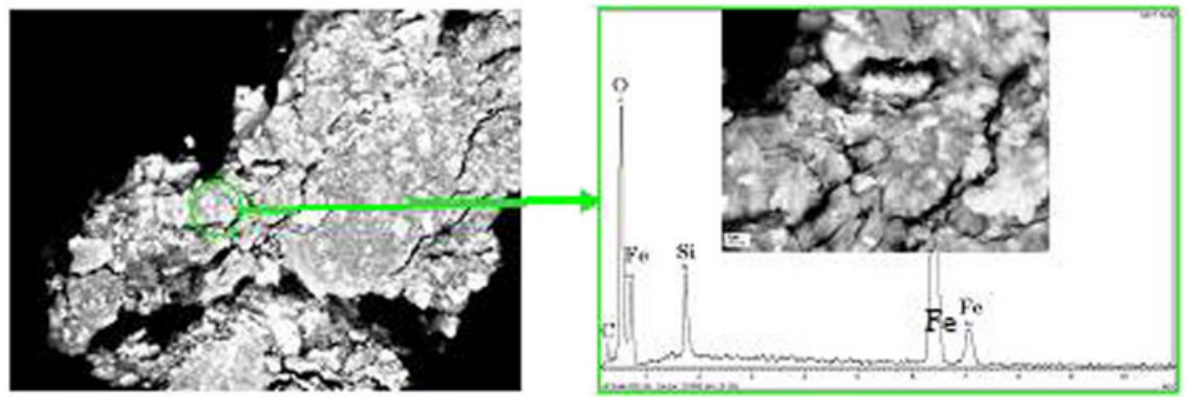

Back scatter images, $5,000 x$ magnifications

Element analvsis

(b) $92 \times 10^{3}$ strokes

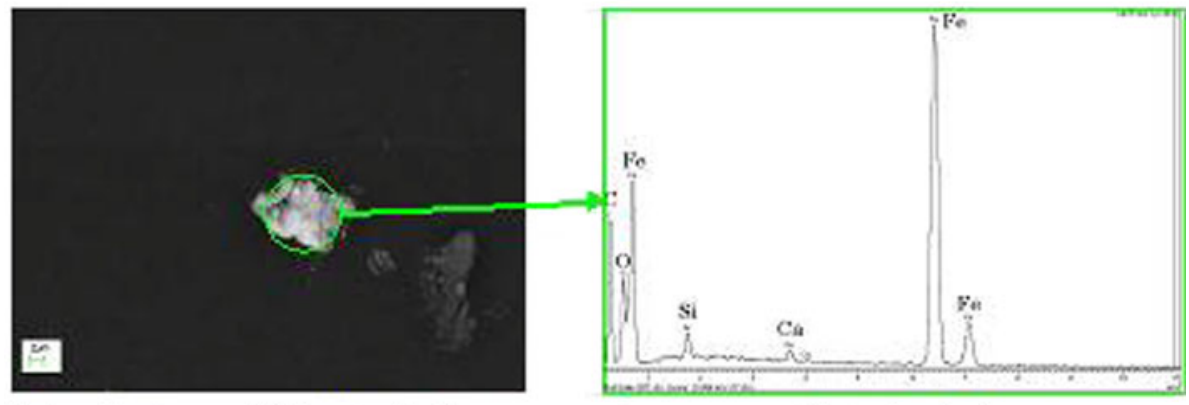

Back scatter images, 5,000x magnifications

Element analysis

(c) $120 \times 10^{3}$ strokes

particles. However, the jagged wear surface regions are not protected from oxidation because the calcium sulphonate surfactants are not inserted into that regions [12]. Therefore, the jagged delamination regions are domains easily adsorbing oxygen.

\subsection{Magnetic Field Effect on Lubricated Wear}

It is postulated that generation of shallow delamination area is caused by the lack of the calcium sulphonate surfactant at the contact interface. Calcium sulphonate surfactants prevent adsorption of oxygen to the wear surface and wear particles. If the calcium sulphonate surfactants do not cover the wear particles and the surface of contact zone, it is expected that iron wear particles are attracted to the wear surface of the plate specimen. Then, the tangential load creates the shallow delamination area and scratches on the wear track of the plate specimen. In particular, the delamination region may be easily oxidised indicating increased surface reactivity of the plate due to magnetisation [6].

Whilst the influence of magnetic field reduces the mass loss of the plate under lubricated sliding, however, high magnetic flux density diminishes the effectiveness of wear reduction compared with low magnetic flux density and produces the delamination area on the wear track as a whole. These evidences suggest that the strength of magnetic flux density relates to the trapping of iron wear particles. In the wear particle formation, lubricated sliding wear under the influence at the magnetic field produces the 
Fig. 9 XRD analyses of wear debris after $120 \times 10^{3}$ strokes

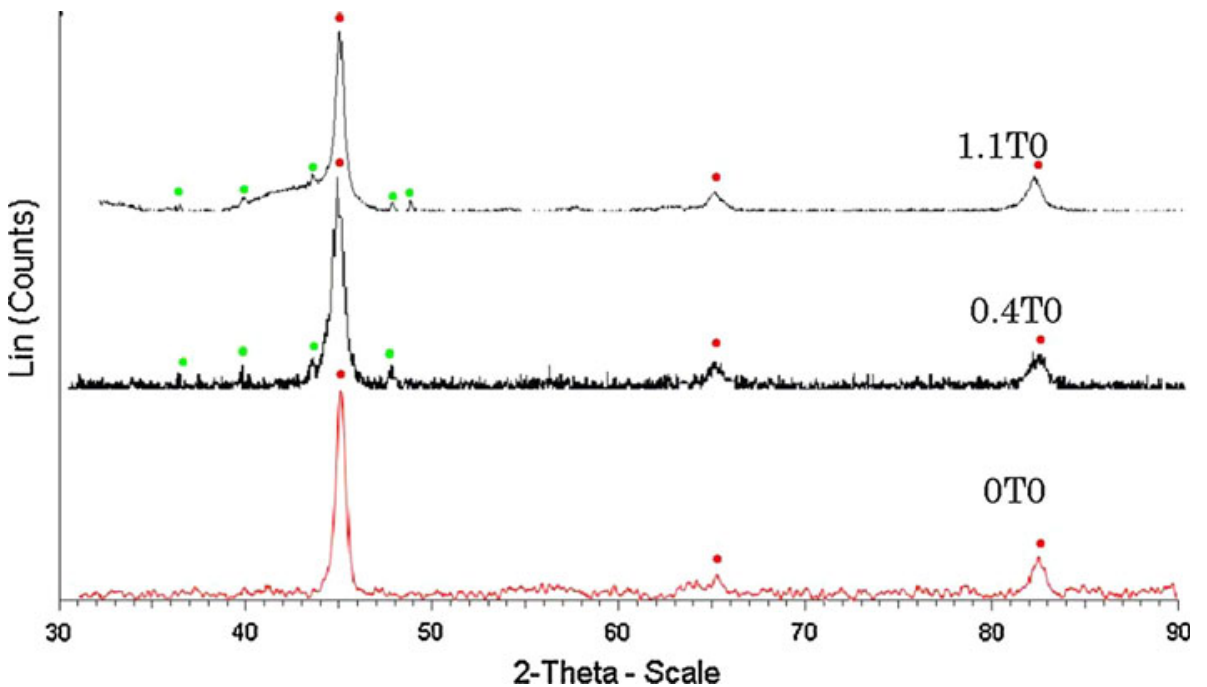

split flaky particles because the iron wear particles at the interface between contacting specimens are compressed.

\subsection{Suggested Lubricated Wear Mechanism in the Presence of Magnetic Field}

In lubricated sliding contact without magnetic field, wear debris produced are not attracted by the surface of specimens in order to be covered individually by the calcium sulphonate surfactant. In addition, the production of wear debris is continuously accumulating at the interface, and thus accelerates the abrasive action. Also, oxygen is not adsorbed to the iron wear particles and the wear surface of the plate specimen.

When magnetic field is present, it removes the iron wear particles from the interface region between specimens and increases the fluidity of lubricant. Lubricated sliding wear polishes the interface and produces fine wear particles. Besides, iron wear particles produced are moved to the outside of wear track by the influence of magnetic field (see Fig. 10a). Scratches on the plate specimen are mainly created by silicon wear particles. Iron wear particles are mainly responsible for delamination. In addition, the wear surface created by magnetisation attracts the iron wear particles and induces the transfer of the wear particles (see Fig. 10b). However, the calcium sulphonate surfactant $\left(\mathrm{Ca}^{++}\right.$and $\left.\mathrm{CaCO}_{3}\right)$ does not reinsert itself to the delamination region, hence, the region is open to oxidisation. The wear with magnetic field is decreased comparing with those without magnetic field because wear debris are removed from interface region by magnetic field. High magnetic flux density increases the transfer of particles on the wear surface of the plate specimen, therefore, the surface mainly consists of jagged delamination regions leading to wear increase.

\section{Conclusions}

Experimental study presented in this article produced results which can be used as a basis for the formulation of the following conclusions:

- The jagged delamination regions produced in the presence of a magnetic field can be regarded as easily

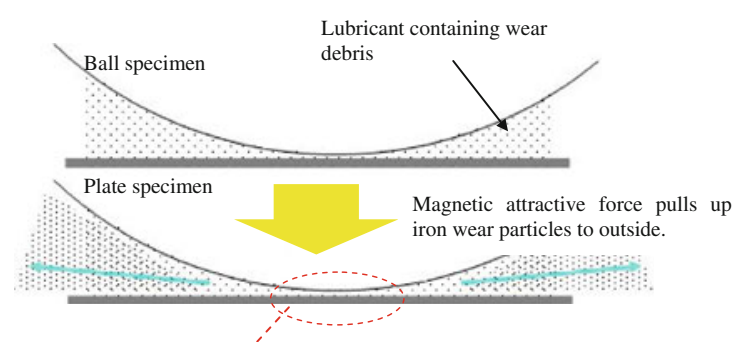

(a) Under presence of magnetic field

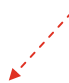

Plate and debris are covered by $\mathrm{Ca}^{++}$and

$\mathrm{CaCO}_{3}$, therefore are able to repel oxygen. Oxyge

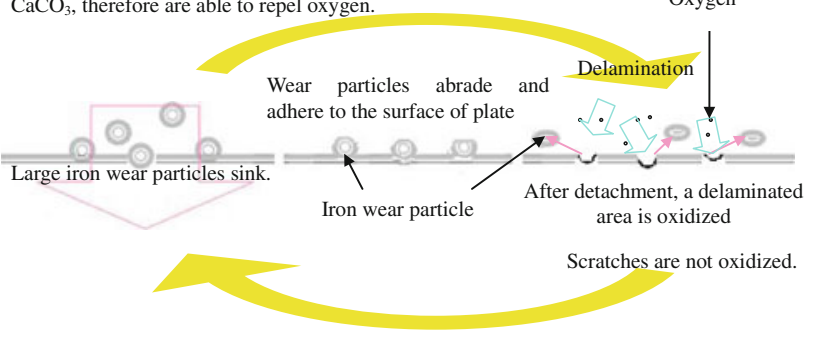

$\mathrm{Ca}^{++}$and $\mathrm{CaCO}_{3}$ adsorb plate and debris and are lost along with body debris.

The oxidized delamination region causes wear reduction.

(b) Detail description of the lubricated wear mechanism in presence of magnetic field

Fig. 10 Proposed lubricated wear mechanism in the presence of magnetic field 
undergoing oxidisation because oxygen is readily adsorbed there.

- Magnetic field is likely to intensify the abrasive action by wear particles.

- Wear, measured as mass loss of plate specimen, tends to be reduced.

It is postulated that all the above is caused by the influence of magnetic field on the electrical charge of the worn surface created on $\mathrm{Si}_{3} \mathrm{~N}_{4}$ ball.

Open Access This article is distributed under the terms of the Creative Commons Attribution License which permits any use, distribution, and reproduction in any medium, provided the original author(s) and the source are credited.

\section{References}

1. Scott, M.F., Bharat, B.: In situ studies of wear mechanisms in magnetic thin-film disks. Tribol. Trans. 40, 549-558 (1997)

2. Chikazumi, C.: Physics of magnetism. Wiley, New York (1964)
3. Muju, M.K., Ghosh, A.: A model of adhesive wear in the presence of a magnetic field. Wear 41, 103-116 (1977)

4. El Mansori, M., Zaidi, H., Kardiri, K.E., Paulmier, D.: Surface modifications of a non-ferromagnetic copper/ferromagnetic steel XC48 couple in magnetized sliding contact. Surf. Coat. Technol. 86-67, 511-515 (1996)

5. Zaidi, H., Chin, J.K., Frene, J.: Analysis of surface and subsurface of sliding electrical contact steel/steel in magnetic field. Surf. Coat. Technol. 148, 241-250 (2001)

6. Yamamoto, Y., Gondo, S.: Effect of a magnetic field on boundary lubrication. Tribol. Int. 20, 342-346 (1987)

7. Muju, K., Radhakrishna, A.: Wear of non-magnetic materials in the presence of a magnetic field. Wear 58, 49-58 (1980)

8. Kumagai, K., Suzuki, L., Kamiya, O.: Study on reduction in wear due to magnetization. Wear 162-164, 196-201 (1993)

9. Kumagai, K., Kamiya, O.: Effects of magnetization on wear. Tribol. Trans. 40, 621-626 (1997)

10. Tallian, T.E.: The theory of partial elastodydrodynamic contacts. Wear 21, 18-27 (1972)

11. Macmillan, N.H., Huntington, R.D., Westwood, A.R.C.: Chemomechanical control of sliding friction behavior in non-metals. J. Mater. Sci. 9, 697-706 (1974)

12. Scherge, M., Martin, M.J., Pohlmann, K.: Characterization of wear debris of systems operated under low wear rate conditions. Wear 260, 458-461 (2006) 